\title{
Nurses' perception of the quality of the Rapid Response Team
}

\author{
Percepção de enfermeiros sobre a qualidade do Time de Resposta Rápida \\ Percepción de enfermeros sobre la calidad del Equipo de Respuesta Rápida
}

\section{Ágatha Stahl de Queiroz' \\ ORCID: 0000-0001-8094-9141 \\ Lilia de Souza Nogueira' \\ ORCID: 0000-0001-5387-3807}

'Universidade de São Paulo, School of Nursing. São Paulo, São Paulo, Brazil.

How to cite this article:

Queiroz AS, Nogueira LS. Nurses' perception of the quality of the Rapid Response Team. Rev Bras Enferm [Internet]. 2019;72(Suppl 1):228-34. [Thematic Issue: Work and Management in Nursing]. DOI: http://dx.doi.org/10.1590/0034-7167-2017-0168

Corresponding Author:

Ágatha Stahl de Queiroz E-mail: agatha.queiroz@usp.br

Submission: 04-03-2017

Approval: 05-25-2018

\begin{abstract}
Objective: verify the perception nurses have of the quality of the Rapid Response Team in the structure, process and outcome dimensions, as well as the influence of time of practice in the institution and the work shift of the professionals on this perception. Method: cross-sectional study, conducted between September and October 2016, with questionnaires to 55 nurses working in inpatient care units or members of the Rapid Response Team. The positive index and inferential tests were used in the data analysis. Results: a satisfactory positive index was identified in 25 of the 37 items analyzed, and the main frailties occurred in the process dimension. There was discrepancy in the perception of professionals with different length of time in the institution about medical consumables $(p=0.05)$ and request for the Rapid Response Team $(p=0.03)$, besides the work shift and communication among the members involved $(p=0.02)$. Conclusion: the nurses' perception of the quality of the Rapid Response Team is satisfactory, especially in the areas of structure and outcome.
\end{abstract}

Descriptors: Rapid Response Team of Hospitals; Quality Management; Nursing; Inpatient Care Units; Cardiology.

\section{RESUMO}

Objetivo: verificar a percepção de enfermeiros sobre a qualidade do Time de Resposta Rápida nas dimensões estrutura, processo e resultado, bem como a influência do tempo de atuação na instituição e o turno de trabalho dos profissionais nessa percepção. Método: estudo transversal, realizado entre setembro e outubro de 2016, com aplicação de questionário a 55 enfermeiros de unidades de internação ou integrantes do Time de Resposta Rápida. Utilizaram-se o índice de positividade e testes inferenciais na análise dos dados. Resultados: identificou-se índice de positividade satisfatório em 25 dos 37 itens analisados, e as principais fragilidades ocorreram na dimensão processo. Houve discrepância na percepção dos profissionais com diferentes tempos de atuação na instituição quanto a materiais de consumo médico-hospitalar $(p=0,05)$ e decisão de acionamento do Time de Resposta Rápida $(p=0,03)$, além do turno de trabalho e comunicação entre os membros envolvidos $(p=0,02)$. Conclusão: a percepção dos enfermeiros sobre a qualidade do Time de Resposta Rápida é satisfatória, especialmente nos domínios estrutura e resultado.

Descritores: Equipe de Respostas Rápidas de Hospitais; Gestão da Qualidade; Enfermagem; Unidades de Internação; Cardiologia.

\section{RESUMEN}

Objetivo: verificar la percepción de enfermeros sobre la calidad del Equipo de Respuesta Rápida en las dimensiones estructura, proceso y resultado, así como la influencia del tiempo de actuación en la institución y el turno de trabajo de los profesionales en esa percepción. Método: estudio transversal, realizado entre septiembre y octubre de 2016, con aplicación de cuestionario a 55 enfermeros de unidades de internación o integrantes del Equipo de Respuesta Rápida. Se utilizaron el índice de positividad y pruebas inferenciales en el análisis de los datos. Resultados: se identificó índice de positividad satisfactorio en 25 de los 37 ítems analizados, y las principales fragilidades ocurrieron en la dimensión proceso. Se observó una discrepancia en la percepción de los profesionales con diferentes tiempos de actuación en la institución en cuanto a materiales de consumo médico-hospitalario $(p=0,05)$ y decisión de accionamiento del Equipo de Respuesta Rápida ( $\mathrm{p}=0,03$ ), además del turno de trabajo y comunicación entre los miembros involucrados $(p=0,02)$. Conclusión: la percepción de los enfermeros sobre la calidad del Equipo de Respuesta Rápida es satisfactoria, especialmente en los dominios estructura y resultado.

Descriptores: Equipo Hospitalario de Respuesta Rápida; Gestión de la Calidad; Enfermería; Unidades de Internación; Cardiología. 


\section{INTRODUCTION}

The creation of quality care systems originally occurred in the industrial sectors of Japan, United States of America (USA) and European countries in the 1950s and stimulated theories about how the production of materials and services can achieve continuous quality improvement (CQI) ${ }^{(1)}$.

$\mathrm{CQI}$ in the healthcare field is based on the implementation and evaluation of management variables that provide to institutions adequate organization and implementation of systems that benefit the work of professionals, always in search of clarity, focus, discipline and commitment in healthcare ${ }^{(2)}$.

Avedis Donabedian, scholar in quality of healthcare management, stated that the evaluation process of the quality is the primary way to determine the degree of success of the professional and that by monitoring the quality, deviations of the standards established can be detected and corrected early ${ }^{(3)}$. Researchers point out that, when using the triad of Donabedian in evaluations (focus on structure, process and outcome dimensions), it is possible to characterize the resources employed in the assistance provided, the typical elements of the practice and state of health of the individual as an outcome of this interaction ${ }^{(4)}$.

The concern with quality in health is evidenced by the movement of large institutions that aim to systematize practices and processes $^{(1,5)}$. In 2004, the Institute for Healthcare Improvement (IHI) promoted in the USA the challenge titled "100,000 Lives Campaign" with the goal of reducing the rates of morbidity and mortality in health care ${ }^{(6-7)}$. Among the targets proposed for hospital institutions, we highlight the implementation of the Rapid Response Team (RRT), which focuses on the qualification of a specialized team able to confirm and act under signs of clinical decline of hospitalized patients in non-critical care units, preventing cardiorespiratory arrest (CRA) and reducing hospital mortality ${ }^{(6)}$.

The American Heart Association (AHA), after analyzing the outcomes on the care of patients with cardiovascular problems and establishing guidelines of assistance, guides the best practice to the health professionals involved. In 2015, AHA conducted the latest update of these guidelines and proposed the need to not only understand and perform the practice of cardiopulmonary resuscitation (CPR), but also to recognize the clinical worsening of patients in several scenarios, guaranteeing the efficiency of healthcare systems and the CQI of the assistance ${ }^{(8)}$.

Given this context, the insertion of RRT in the first link within the chain of survival of AHA (called "surveillance and prevention") for patient care in CPR in the intra-hospital environment (CPRIH), besides promoting the early identification of these events, reduces the number of CPRs that occurred outside the Intensive Care Unit $(\mathrm{ICU})^{(9)}$, minimizes the number of admissions in critical care units and mortality rates ${ }^{(2)}$, thus ensuring the CQI of the assistance provided to patients in imminent hemodynamics instability ${ }^{(10)}$.

CPRIH events can occur in hospital wards, where continuous clinical monitoring equipment is not provided, so RRT is strongly recommended in these units. RRT must be formed by a multidisciplinary team that, with a good interaction and scientific and technical skills, may, from the request made by the professional who recognizes the clinical changes of the patient, quickly confirm them and give CPR or other clinical treatment, if appropriate, with effectiveness and quality ${ }^{(2)}$.

It is noteworthy that, historically, nursing is known due to the surveillance and constant monitoring of the clinical signs of patients and, therefore, the nurse is the protagonist in the early detection of CPR and in quick decision-making to request RRT, since such skills possibly come from the experience coupled to memories of past situations or intuition ${ }^{(10-12)}$.

The codes to request RRT, able to translate the unstable condition of the patient or CPR into a single signal ${ }^{(13)}$, are tools that have been helping the daily life of nurses who work in non-critical care units $^{(11-12)}$. However, to optimize decision-making in these situations, it is necessary for the care and risk management to be organized and well structured, promoting clinical stability, safety and welfare of patients under the glances of the nursing staff. In addition, the interprofessional, organizational and institutional barriers should be identified and removed for influencing the process of identification, response and reduction of adverse events ${ }^{(14)}$.

Whereas setting goals and changing processes depend on the regular measurement of care, understanding better the dynamics of RRT (its structure, process and outcome) through the experiences of nurses allow us to identify how this resource impacts the workplace, the RRT configuration itself and the care provided $^{(5,15)}$, and since little is known about this approach, the importance of this research is justified.

\section{OBJECTIVE}

Verify the perception nurses have of the quality of RRT in the structure, process and outcome dimensions, as well as to identify whether the time of practice in the institution and the work shift of the professionals influence this perception.

\section{METHOD}

\section{Ethical aspects}

This study was approved by the Research Ethics Committee of the School of Nursing of the University of São Paulo.

\section{Design, location and period}

This is a cross-sectional and quantitative study, developed between September and October 2016 in a public hospital of high complexity, specialized in cardiopulmonology, located in the city of São Paulo, Brazil, where TRR was instituted five years ago ${ }^{(13)}$.

\section{Population or sample: inclusion and exclusion criteria}

The sample consisted of nurses who worked as members of RRT or in the direct assistance to patients in one of the inpatient care units of the institution (non-critical care units). The professionals who were on vacation or on sick leave during the period of data collection were excluded. Of the 76 professionals invited to participate in the study, ten refused and eleven did not return the data collection instrument completed, accounting for a final sample of 55 professionals. 


\section{Study protocol}

After approval by the Research Ethics Committee, a list containing the names of the nurses who responded to the inclusion criteria of the survey was requested to the nursing coordination of the institution.

The nurses were invited to participate in the study by the researcher, who explained the objectives and the process of collecting the information. After signing the informed consent form (ICF), the questionnaire was handed at the beginning of the shift, collected after the period established in accordance with the convenience of each participant.

This questionnaire was composed of two parts. The first one dealt with aspects related to the demographic, educational and professional profile of the participants, in addition to information about knowledge and request for RRT and certification in Basic Life Support (BLS) and/or Advanced Cardiac Life Support (ACLS).

The second part contained an instrument created and validated in 2014 by researchers of the State University of Londrina (UEL), in Paraná, which aims to address the representative dimensions that impact the care of RRT: structure (physical resources, human, material, equipment, rules, routines, value systems and expectations); process (analysis of the development of assistance according to technical and scientific standards accepted internationally); and outcome (consequences of the activities performed). For the structure dimension, nine statements were described (E1 to E9); for process, twenty (P1 to P20); and for outcome, eight (R1 to R8). The response options include the categories "yes," "no" or "not applicable"(5). The use of this instrument in the study had the permission of the researchers responsible for its creation.

\section{Analysis of the results and statistics}

Descriptive statistics were performed for sample characterization. The positive index (PI) $)^{(16-17)}$ was applied to each one of the 37 items of the questionnaire separately, considering the answers "yes" or "no" of the subject of the research. The answer "does not apply" contained in the instrument of collection reflects the non-exposure of the patient and/or professional to the condition described in the respective item and, therefore, was excluded from the analysis.

PI was applied to each item and used to calculate the average of each dimension, from the application of the equation described later. Based on the literature consulted ${ }^{(16-17)}$, the $\mathrm{PI}$ value $\geq 70 \%$ was adopted as parameter to evaluate the quality of care of RRT.

Positive Index $(\mathrm{PI})=\frac{\text { no.of affirmative answers }}{\text { no.of affirmative answers }+ \text { no of negative answers }} \times 100$

To verify the influence of time of practice in the institution and the work shift (day or night) considering professionals' perception of the quality of RRT, theFisher's Exact Test and the Student's t-test were applied. The software Statistical Package for the Social Sciences (SPSS), version 22 , was used in the statistical analysis with a significance level of $5 \%$.

\section{RESULTS}

Of the 55 nurses that composed the final sample of the study, most were women $(n=50 ; 90.9 \%)$ and exercised direct assistance to the patients $(n=41 ; 74.5 \%)$ in inpatient care units. The average age of the participants was $40.7 \pm 11.2$ years, and 31 professionals (56.4\%) were aged between 25 and 40 years. Little difference was found between the time of qualification (approximate average of sixteen years) and the time of practice of the nurses in the institution (approximate average of fifteen years).

A total of 46 professionals (83.6\%) reported having completed lato sensu graduation courses, with emphasis on the areas of cardiology $(n=34,61.8 \%)$ and hospital administration $(n=11$, $20.0 \%$ ), and 18 (32.7\%) had two or more specializations. As for the international certifications, 40 professionals (72.7\%) concluded the BLS, and $46(83.6 \%)$ the ACLS.

When asked about RRT, all nurses claimed to know the strategy. In the institution, 44 professionals (80.0\%) had already requested RRT at least once, and a total of fourteen nurses (25.5\%) was a member of RRT.

We observed in Tables 1, 2 and 3 that nurses considered the quality of RRT in the institution ( $\mathrm{PI} \geq 70.0 \%)$ satisfactory in 25 $(67.6 \%)$ of the 37 items described in the instrument, and two items reached $\mathrm{PI}$ of $100.0 \%$ (P20 and R1). The average value of PI of the process dimension was $64.8 \%$, while structure and outcome dimensions were $78.7 \%$ and $87.6 \%$, respectively.

The main frailties identified by these professionals ( $\mathrm{Pl}<70.0 \%)$ were related to the process dimension (Table 1). Questions associated with the knowledge of the nurse about the medical conditions of all patients treated in the unit (P9) and the effective communication between doctor of RRT and doctor of the clinic in appointments suggested to patients (P15) reached PI of $68.2 \%$.

Aspects related to the request for RRT by the nurse of the unit based on any change in the patient's condition (P2), educational activities developed by RRT to empower new teams (P10) and nursing staff in the units of practice (P11), as well as the communication between RRT and the nurse in the units during visits to patients (P16), had PI that ranged from $40.5 \%$ to $53.8 \%$.

PI values lower than $10.0 \%$ were identified in activities of RRT aiming at visits to patients in restrained demand (P6), to the establishment of treatment plan for patients in critical care units (P7) and to the daily discussion about the care plan provided with the professionals to patients in restrained demand or classified in codes blue and yellow (P8).

For the structure dimension, unsatisfactory quality of RRT was related to aspects of the physical structure of the unit that does not provide a safe and effective care to patients (E7) and to the absence of an exclusive nurse working with RRT in the institution (E9), as shown in Table 2.

Table 3 shows that the only item of the outcome dimension with negative note $(\mathrm{PI}<70 \%)$ was the lack of monthly disclosure, by the institution or coordinator of RRT, of the outcomes of the services performed in the units (R8).

The following tables show variables with statistically significant differences $(p \leq 0.05)$ in the answers of professionals on RRT according to time of practice in the institution (Table 4) and work shift (Table 5). Table 4 shows that nurses who answered "yes" to questions about medical consumables in sufficient quantities (E3) and about the decision to request RRT relying solely on the signs of clinic deterioration established in codes blue and yellow (P1) showed more time of practice in the institution compared with those who answered negatively to these questions. 
Table 1 - Positive index of nurses' perception of the quality of Rapid Response Team according to the process dimension, São Paulo, Brazil, 2016

P1. The decision to request RRT depends exclusively on the signs of clinical deterioration established in codes blue and yellow.

P2. RRT must also be requested when the nurse of the unit is concerned about any change in the patient's condition, regardless of the stability of vital signs.

P3. The RRT team, when requested, appears in 3 minutes to start the care for the patient in a code blue.

P4. The RRT team, when requested, appears in 4 minutes to start the care for the patient in a code yellow.

P5. During a code blue or yellow in the unit, it is easy to request/locate RRT at the institution.

P6. RRT carries out visits in the morning and afternoon to patients in restrained demand.

P7. RRT participates in the establishment of the treatment plan of critically ill patients in the unit.

P8. RRT discusses daily the assistance plan with the professionals (nurses, emergency physician, resident physician) involved in the care

for patients in restrained demand or in codes blue and yellow.

P9. The nurse knows the clinical conditions of all patients treated by RRT on the unit under her/his supervision, as well as the behavior and prescribed treatments.

P10. RRT develops educational activities, qualifying new RRT for the treatment of critically ill patients in the units.

P13. RRT has a research/study group formed by the RRT staff and by professionals of the units.

P14. It is essential to monitor critically ill patients in restrained demand, due to the difficulty of immediate transfer to the Intensive Care Unit.

P15. Effective communication occurs between the doctor of TRR and the clinic doctor in appointments suggested to patients.

P16. RRT communicates with the nurse when visiting patients in the care units.

P17. Communication between members of RRT and the nurse of the unit is effective, clear and objective.

P18. RRT professionals are accessible for the codes yellow and blue and or restrained demand.

P19. The nurse of the unit follows the code blue during the whole service, along with the RRT professionals.

P20. The nurse of the unit follows the code yellow during the whole service, along with the RRT professionals.

Note-Rapid Response Team (RRT)

Table 2 - Positive index of nurses' perception of the quality of Rapid Response Team according to the structure dimension, São Paulo, Brazil, 2016

\section{Structure Dimension}

E1. The nurse is the one responsible for requesting RRT, because he/she is 24 hours beside the patient

E2. Permanent materials (non-invasive blood pressure monitor, cardioscope, pulse oximeter, defibrillator, mechanical fan, secretion aspirator, glucose meter, infusion pump, gas network, among others) are sufficient and available when requested by RRT

E3. Medical consumables (infusion equipment, needled devices, medications, materials for intubation, among others) are available

in sufficient quantities to treat the patients assisted by RRT.

E4. Patients treated by RRT in the unit have the resources in the nursing staff qualified and in sufficient number to provide the necessary care.

E5. The emergency car of the unit has the necessary materials and equipment, in accordance with the protocol adopted in the institution, for the care of patients by RRT.

E6. The manual/protocol of routines about RRT is available and has easy access to the unit.

E7. The physical structure of the unit provides a safe and effective care (without ramp, wide doors, adequate space between beds, lighting, electrical network, gas network, monitor countertop/infusion pump) to patients.

Table 3 - Positive index of nurses' perception of the quality of Rapid Response Team according to the outcome dimension, São Paulo, Brazil, 2016

\begin{tabular}{l} 
Outcome Dimension \\
\hline R1 With the assistance of the doctor and of RRT provided concurrently, I have greater security in the implementation of the nursing care \\
provided in the unit under my supervision. \\
R2. As a nurse I am not afraid to take criticism from the institution or from the coordinator of RRT, for requiring the service staff, when \\
patients do not meet the criteria established by the protocol. \\
R3. The differential service proposed by RRT to the patient in restrained demand and/or monitored for 72 hours after discharge from the \\
Intensive Care Unit improves the assistance provided to patients. \\
R4. It is essential to implement RRT at night in the institution \\
R5. RRT reduces the risk of clinical deterioration of patients in the units. \\
R6. RRT reduces the mortality rate of patients in codes blue and yellow or restrained demand. \\
R7. RRT and the nursing staff of the unit under my supervision have a good interpersonal relationship. \\
R8. Every month the institution or the coordinator of RRT provide the outcomes of the services performed in the units. \\
\hline
\end{tabular}


Table 4 - Comparison of the averages of time of practice in the institution according to responses from nurses about the quality of the Rapid Response Team, São Paulo, Brazil, 2016

\begin{tabular}{cccc}
\hline Variables & Categories & $\begin{array}{c}\text { Time of practice in the } \\
\text { institution } \\
\text { Mean (Standard Deviation) }\end{array}$ & $\boldsymbol{p}$ value* \\
\hline E3. & Yes & $15.3(9.6)$ & 0.05 \\
& No & $5.7(1.7)$ & \\
P1. & Yes & $16.1(9.1)$ & 0.03 \\
& No & $8.4(9.1)$ & \\
\hline
\end{tabular}

Note: *Student's t-test.

Table 5 - Comparison of nurses' responses about the quality of the Rapid Response Team according to work shift, São Paulo, Brazil, 2016

\begin{tabular}{|c|c|c|c|c|}
\hline \multirow[b]{2}{*}{ Variables } & \multirow[b]{2}{*}{ Categories } & \multicolumn{2}{|c|}{ Work shift } & \multirow[b]{2}{*}{$p$ value* } \\
\hline & & $\begin{array}{c}\text { Daytime } \\
\text { n (\%) }\end{array}$ & $\begin{array}{c}\text { Nighttime } \\
\text { n (\%) }\end{array}$ & \\
\hline \multirow[t]{2}{*}{ P17. } & Yes & $33(97.1)$ & $9(69.2)$ & \\
\hline & No & $1(2.9)$ & $4(30.8)$ & 0.02 \\
\hline
\end{tabular}

Note: *Fisher's Exact Test

Regarding work shift, Table 5 shows that the professionals who worked at night responded with greater frequency the alternative "no" to the item on effective, clear and objective communication between the members of RRT and the nurse of the unit (P17) than those who worked during the day (30.8\% versus $2.9 \%$, respectively).

\section{DISCUSSION}

The results of this research showed that the nurses' perception of the quality of RRT of the institution is satisfactory, since $67.6 \%$ of the items analyzed presented PI higher than $70.0 \%$. The quality of this strategy can be a result of the careful implementation process adopted by the institution, as described in case report (13), which created a culture in the hospital and in the health teams, promoting the conscious use of RRT and the reasons to request it. We must also consider the uniqueness of the professionals working at this hospital: they have long time of practice in the institution (15.3 \pm 9.6 years) and seek to update the good practice, which is identified by the high frequency of professionals who concluded graduation courses (83.6\%) or participated in immersion courses about CPR, such as BLS (72.7\%) and ACLS (83.6\%).

Study conducted in a university hospital in the state of Paraná that analyzed the quality of care of RRT, based on the triad of Donabedian, identified average PI of $45.96 \%$ for structure, $56.54 \%$ for process and $74.99 \%$ for outcome ${ }^{(17)}$, values below those of this investigation in all dimensions.

However, whereas the process would be the most direct way to assess the quality of care, we identified that such dimension was the one that obtained more items with lower PI values, and such finding must have a distinctive look.

The PI value of $42.0 \%$ was identified in the question on the request for RRT in the presence of any changes in the patient's condition, regardless of the stability of his/her vital signs (P2). From this perspective, researchers from Australia point out that the experience in activating the strategy improperly can cause frustrations and, consequently, reduce the number of requests, once the decision to request RRT and the understanding about the policies of this strategy are often not clear to the professionals ${ }^{(18)}$.

Some aspects of the process that reached PI values below $8.0 \%$ were related to RRT visits to patients in restrained demand (P6), to the participation of RRT in establishing treatment plans for critically ill patients (P7) and in daily discussion with the professionals about the care provided (P8). Considering the low availability of ICU beds in Brazil and that delays in admissions in these units lead to increase in mortality, it is noteworthy that the use of these measures described and evaluated as fragile by the nurses could optimize the care and safety of patients awaiting intensive care beds in non-critical units, preventing deterioration and increasing the chances of recovery ${ }^{(17)}$. However, these strategies (P6 to P8) are not provided for in the protocol of RRT in the institution where the research was conducted.

Another item that reached unsatisfactory $\mathrm{PI}(\mathrm{PI}=68.2 \%)$ was the question on the knowledge of the nursing staff about the clinical conditions of all patients treated by RRT (P9). This fact can be coupled to another item, which concerns the promotion of educational activities (P11) for nurses working in inpatient care units $(\mathrm{PI}=53.2 \%)$. Results of the research conducted in North Carolina, USA, showed that nurses consider RRT a good teaching tool and a source of knowledge to assist in the care and in the strengthening of their capacities, as well as in decisions about the correct time to request the staff, placing them as a fundamental part of the teams during the emergency. The focus group methodology employed in this study identified, in the reports of professionals, that the requests are rarely erroneous, thereby, the teamwork with RRT is always valid ${ }^{(15)}$.

Other investigations report a considerable number of nurses who express the need for additional training and education programs about emergency, seeking to refine the early recognition skills of the signs of clinical deterioration in order to play a more active and assertive role in this context ${ }^{(18-20)}$.

From the professional education perspective, the PI value was equal to $53.8 \%$ in relation to capacity and training of new teams in the institution (P10). Some authors underline the need for institutions to prioritize the intensive and continued training of new professionals (doctors, nurses and physiotherapists), once the high turnover of these members and the recurrent failed communication with the nursing staff of non-critical care units can compromise the patient's safety during clinical instability ${ }^{(19)}$.

Communication proved to be weak between RRT, the doctors (P15) and the nurses of the units (P16). Positive interactions between the teams provide better reviews about the context of the emergency and allow quicker access to exams and procedures, in addition to facilitating transfers to ICU, promoting safety to the critically ill patient and relief to the professionals who request $\mathrm{RRT}^{(15)}$. For some nurses, this interaction is often hindered because RRT seem resistant to their considerations, which they ascribe to the fact RRT does not participate in the daily evolution of the critically ill patient ${ }^{(15)}$.

In the analysis of the structure dimension, this study showed frailty (PI value of $43.6 \%$ ) to provide safe and effective care because 
of the physical environment of the unit (E7). This finding corroborates the Brazilian study that mentions the impact of the infrastructure of health services on the work process and on the quality of nursing care. According to the researchers, the nurse's practices are influenced by different characteristics of services, such as the availability, limitations and the quality of the instruments or means of work, since the lack of such tools undermines the work of the teams and their results. Therefore, the working environment must be able to promote health and prevent diseases, resulting in the expansion of the possibilities of practice for nurses within the unit he/she operates ${ }^{(21)}$.

Another unsatisfactory $\mathrm{PI}(\mathrm{PI}=64.7 \%)$ of the structure dimension (E9) on the perception of the participants referred to the presence of exclusive nurses in the institution working in RRT. It is noteworthy that the institution does not provide for such exclusivity, optimizing human resources. However, it is important that all members of the team are known by non-critical care units, which facilitates the communication at the time of the assistance.

Finally, the outcome dimension had on average high PI values, indicating that the services provided have, in the nurses' perception, a high degree of quality. The only item that does not exceed the margin of positivity $(\mathrm{Pl}<70.0 \%)$ referred to nurses' access to the outcomes of the assistance performed by RRT in the unit (R8). In the management approach of the quality of the health service, Donabedian and other researchers reinforce that the use of assistance indicators encourages the professionals and lowers their resistance to request RRT; in other words, the care and its results no longer represent an abstract and subjective ambition, thus enabling the service to be, above all, improved ${ }^{(4,17)}$.

Our study identified that nurses with more time of practice in the institution think medical consumables are in sufficient quantities and recognize that the decision to request RRT depends exclusively on the signs of clinical deterioration established in codes, unlike nurses with less time in the institution.

We identified three surveys that examined nurses' perceptions of RRT considering the variable time in profession or in the institution. Some authors concluded that the request for RRT by more experienced nurses may be falling short of the ideal, since they are more resistant to requesting the service ${ }^{(19)}$. Opposite results were found in studies that concluded nurses with less experience (between zero and five years) are less likely to activate the codes in relation to those working there for a longer period (eleven years or more) ${ }^{(18)}$. This fact it is associated with the insecurity of these professionals in decision-making, with their lack of knowledge of processes and institutional outcomes, in addition to holding clinical judgements less accurate - i.e. they have less autonomy and consult more the practices to be performed ${ }^{(18,20)}$.

As to the association between work shift and the perception of effectiveness, clarity and objectivity of communication between members of RRT and the nurse of the unit, this study identified statistically significant difference between the daytime and nighttime groups, because the professionals who worked at night were those that gave more negative answers. Studies that cover such topic were not identified in the literature. Only one investigation in Australia showed no significant difference in the frequency of request for RRT among nurses who worked part-time and full-time ${ }^{(18)}$. It must be considered that in most hospitals some sectors work with a small number of professionals on night duty, since the demand of patients during this period is reduced; it can be assumed that this fact negatively impacts communication between teams.

\section{Limitations of the study}

By analyzing the results of this research - which showed important aspects of nurses' perception of the quality of RRT, as well as points to be improved -, some limitations should be considered in the generalization of results: the casuistry included only nurses from one hospital, reference center for the care of patients with cardiopulmonary diseases; there was approximately $27.6 \%$ loss of the casuistry expected; and the response time of the instrument varied among the nurses.

\section{Contributions to the fields of nursing, health, or public policy}

The results of this investigation provide information to assist managers in the development of strategies and tools for the improvement of the quality of RRT and permanent education of the team involved directly in the dynamics of rescue of critically ill patients in inpatient care units, translating their potential into safe assistance.

\section{CONCLUSION}

The findings of this research allow to conclude that RRT in the institution analyzed presents, in the perception of nurses, satisfactory quality in the structure and outcome dimensions. Vulnerabilities were identified, especially in relation to some items of the process, which obtained the lowest average of $\mathrm{PI}$ value in relation to the other dimensions.

The study also identified that the professionals with more experience in the hospital feel that the medical consumables are in sufficient quantities to treat the patients and that the decision to request RRT depends exclusively on signs of clinical deterioration established in codes blue and yellow, which differs from the perception of nurses with less experience in the institution. In addition, more professionals on night duty consider that communication between the members of RRT and the nurse of the unit is not effective, compared with those who work during the day.

Considering the results of the research, we suggest the preparation of strategies to improve the quality of RRT, especially regarding the process dimension, which presented greater frailty according to the nurses.

\section{REFERENCES}

1. D'Innocenzo M, Adami NP, Cunha ICKO. [The moviment for quality in healthcare and nursing services]. Rev Bras Enferm [Internet]. 2006 [cited 2018 Aug 14];59(1):84-88. Available from: http://dx.doi.org/10.1590/S0034-71672006000100016 Portuguese. 
2. Kronick SL, Kurz MC, Lin S, Edelson DP, Berg RA, Billi JE, et al. Part 4: systems of care and continuous quality improvement: 2015 American Heart Association Guidelines Update for Cardiopulmonary Resuscitation and Emergency Cardiovascular Care. Circulation [Internet]. 2015[cited 2018 Aug 14];132(suppl 2):S397-S413. Available from: http://circ.ahajournals.org/content/132/18_suppl_2/S397.full. doi: doi: 10.1161/CIR.0000000000000258.

3. Donabedian A. An introduction to quality assurance in health care. Oxford: University Press; c2013. Chapter 5: Formulating criteria and standards. p. 59-61.

4. Reis EJFB, Santos FP, Campos FE, Acúrcio FA, Leite MTT, Leite MLC, et al . Avaliação da qualidade dos serviços de saúde: notas bibliográficas. Cad Saúde Pública [Internet]. 1990 [cited 2018 Aug 14];6(1):50-61. Available from: http://dx.doi.org/10.1590/S0102-311X1990000100006

5. Dias AO, Martins EAP, Haddad MCL. [Instrument for assessing the quality of the Rapid Response Team at a university public hospital]. Rev Bras Enferm [Internet]. 2014[cited 2018 Aug 14];67(5):700-7. Available from: http://dx.doi.org/10.1590/0034-7167.2014670505. Portuguese.

6. Berwick DM, Calkins DR, McCannon CJ, Hackbarth AD. The 100,000 lives campaign: setting a goal and a deadline for improving health care quality. JAMA [Internet]. 2006[cited 2018 Aug 14];295(3):324-7. Available from: http://jama.jamanetwork.com/article.aspx?articleid=202194

7. Institute for Healthcare Improvement. Overview [Internet]. Boston (MA): Institute for Healthcare Improvement, c2018. [cited 2018 Aug 14]. Available from: http://www.ihi.org/engage/initiatives/completed/5MillionLivesCampaign/Pages/default.aspx

8. Neumar RW, Shuster M, Callaway CW, Gent LM, Atkins DL, Bhanji F, et al. Part 1: Executive Summary. Circulation [Internet]. 2015[cited 2018 Aug 14];132(18 Suppl 2):S315-67. Available from: http://circ.ahajournals.org/content/132/18_suppl_2/S315.full

9. Chan PS, Jain R, Nallmothu BK, Berg RA, Sasson C. Rapid Response Teams: a systematic review and meta-analysis. Arch Intern Med. 2010;170(1):18-26.

10. Al Qahtani S. Satisfaction survey on the critical care response team services in a teaching hospital. Int J Gen Med [Internet]. 2011 [cited 2018 Aug. 14];4:22-4. Available from: http://www.pubmedcentral.nih.gov/articlerender.fcgi?artid=3085231\&tool=pmcentrez\&re ndertype $=$ abstract

11. Tait D. Nursing recognition and response to signs of clinical deterioration. Nurs Manag (Harrow). 2010;17(6):31-5.

12. Cioffi J. Nurses' experiences of making decisions to call emergency assistance to their patients. J Adv Nurs. 2000;32(1):108-14.

13. Lopes JL, Silva RCG, Quilici AP, Palomo JSH, Gonzalez MMC, Ferreira FG. Implementation of Rapid Response Teams: the experience in a highly complex cardiopneumology hospital. Rev Soc Bras Clín Méd. 2012;10(5):394-7.

14. Considine J, Botti M. Who, when and where? Identification of patients at risk of an in-hospital adverse event: implications for nursing practice. Int J Nurs Pract. 2004;10(1):21-31.

15. Williams DJ, Newman A, Jones C, Woodard B. Nurses Perceptions of how Rapid Response Teams affect the nurse, team, and system. J Nurs Care Qual. 2011;26(3):265-72.

16. Aparecida E, Nonino PM, Anselmi ML, Dalmas JC. Quality assessment of the wound dressing procedure in patients at a university hospital. Rev Lat Am Enfermagem [Internet]. 2008 [cited 2018 Aug 14];16(1):57-63. Available from: http://dx.doi.org/10.1590/S010411692008000100010. English, Portuguese.

17. Dias AO, Grion CMC, Martins EAP. Quality analysis of the rapid response team in a university hospital: nurses' opinions. Ciênc Cuid Saúde [Internet]. 2014[cited 2018 Aug 14];14(1):917-23. Available from: http://dx.doi.org/10.4025/cienccuidsaude.v14i1.22919 English, Portuguese.

18. Salamonson $Y$, van Heere B, Everett B, Davidson P. Voices from the floor: nurses' perceptions of the medical emergency team. Intensive Crit Care Nurs. 2006;22(3):138-43.

19. Shapiro SE, Donaldson NE, Scott MB. Rapid response teams seen through the eyes of the nurse. Am J Nurs. 2010;110(6):28-34;quiz35-6.

20. Jenkins SH, Astroth KS, Woith WM. Non-Critical-Care nurses' perceptions of facilitators and barriers to Rapid Response Team Activation. J Nurses Prof Dev. 2015;31(5):264-70.

21. Pedrosa ICF, Corrêa ÁCDP, Mandú ENT. [Perceptions of nurses about the influence of the infrastructure in their practices]. Ciênc Cuid Saúde [Internet]. 2011 [cited 2018 Aug 14];10(1):58-65. Available from: http://periodicos.uem.br/ojs/index.php/CiencCuidSaude/article/ view/13288. Portuguese. 